\section{Commentary: Breaking the perioperative glucose control barrier is like breaking the sound barrier-it takes a team!}

\author{
Victor A. Ferraris, MD, PhD
}

The manuscript by Corazzari and colleagues ${ }^{1}$ presents a meta-analysis of the relationship between patients' glucometabolic status and outcomes following cardiac operations. The authors' meta-analysis includes nearly 35,000 patients accumulated from 30 observational studies and published over a 12-year period (2008-2020). They used an expanded definition of perioperative glucometabolic control to analyze various levels of $\mathrm{HbA} 1 \mathrm{c}$ control ranging from $5.5 \%$ to $7.5 \%$ in increments of $0.5 \%$. They found early mortality reductions in each incremental reduction of HbAlc levels, but the greatest reduction was observed in the group of patients whose $\mathrm{HbA} 1 \mathrm{c}$ was $<5.5 \%$. Further, they found significant associations between lower $\mathrm{HbA} 1 \mathrm{c}$ levels and reduced risks of early and late mortality, as well as postoperative acute kidney injury, neurologic complications, and wound infections. Reductions in each of these postoperative complications had varying benefits related to lower HbA1c levels. The authors' message is that lower HbAlc levels have prognostic significance for cardiac surgical outcomes.

The issue of specific targets of perioperative glucose control is not just a cardiac surgery-specific issue. Several investigations suggest that perioperative glucose control is an important predictor of surgical outcomes in a wide range of operative interventions. For example, postoperative hyperglycemia was associated with adverse events after

\footnotetext{
From the Division of Cardiothoracic Surgery, University of Kentucky \& Lexington VA Medical Center, Lexington, Ky.

Disclosures: The author reported no conflicts of interest.

The Journal policy requires editors and reviewers to disclose conflicts of interest and to decline handling or reviewing manuscripts for which they may have a conflict of interest. The editors and reviewers of this article have no conflicts of interest.

Received for publication May 31, 2021; revisions received May 31, 2021; accepted for publication June 1, 2021; available ahead of print June 22, 2021.

Address for reprints: Victor A. Ferraris, MD, PhD, Division of Cardiothoracic Surgery, University of Kentucky, A301 Kentucky Clinic, 740 South Limestone Ave, Lexington, KY 40536-0284 (E-mail: ferraris@uky.edu).

J Thorac Cardiovasc Surg 2022;164:1961-2

$0022-5223 / \$ 36.00$

Copyright (C) 2021 by The American Association for Thoracic Surgery

https://doi.org/10.1016/j.jtcvs.2021.06.004
}

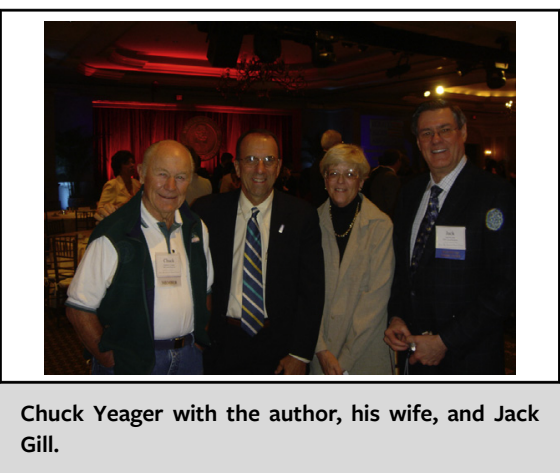

CENTRAL MESSAGE

Perioperative control of glucometabolic status is a treatable metric that is associated with improved surgical outcomes and takes a team to do it.

lower-extremity vascular procedures in patients with and without diabetes ${ }^{2}$ and other surgical procedures. These adverse events included infection, increased hospital use, and operative mortality. Nearly all surgical specialties are plagued by abnormalities in glucose metabolism in the perioperative period.

The authors' results are complex, and the relationship between $\mathrm{HbA1c}$ and various surgical outcomes is not completely linear. The novel observation of this manuscript is that $\mathrm{HbA} 1 \mathrm{c}$ levels represent a continuous risk, ranging between levels of $5.5 \%$ and $7.0 \%$, with some variation in risk profiles at different levels of HbA1c. This risk seems to be nearly independent of whether the patient has known diabetes. The authors have taken on a complex issue and found not-unexpected diversity in outcomes analysis. It seems that the key piece of information presented in the authors' metaanalysis is that measurement of $\mathrm{HbAlc}$ in the perioperative period offers a broad-based indicator of potential for glucose-related complications, independent of whether the patient has known diabetes. This is original and provocative information that should stimulate further research in this area.

The authors' manuscript is heavily weighted toward a complex, nuanced association of perioperative outcomes associated with $\mathrm{HbA1c}$ levels without a more focused statement on recommendations for managing (and reducing) HbA1c levels in the perioperative period. Readers would value this manuscript more if the authors could provide a definitive statement that "lower HbA1c levels are better 


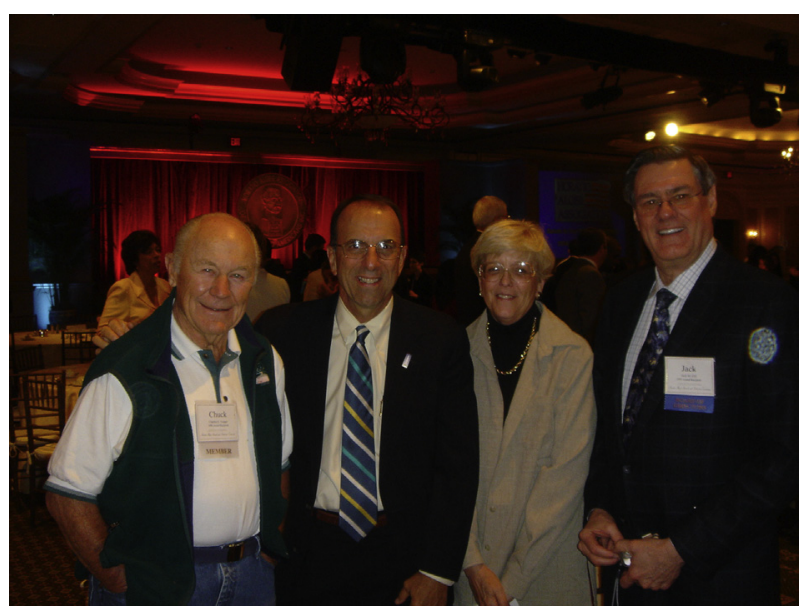

FIGURE 1. Chuck Yeager with the author, his wife, and Jack Gill.

and this should be a target for improving outcomes in all surgical patients." Poor glucose control following cardiac operations has been listed as a "never event" that should be manageable in the perioperative period.

Part of the hesitancy in recommending strict $\mathrm{HbA} 1 \mathrm{c}$ control may reside in the complications of hypoglycemia, especially in patients without diabetes. Reports suggest that a blood glucose level of $140 \mathrm{~g} / \mathrm{dL}$ may be safe and moderately effective for glycemic control. There have been reports of expert systems and dedicated teams that facilitate a safe and effective intensive insulin therapy that results in perioperative glucose control at levels lower than $140 \mathrm{~g} / \mathrm{dL} .{ }^{4}$ These expert systems can be managed by nurse teams at the bedside and seem to be safe and effective. Tighter glucose control is feasible and likely to be associated with improved surgical outcomes but requires team skills and attention to detail.

To summarize, the article by Corazzari and colleagues ${ }^{1}$ offers a bellwether for cardiac surgeons. Optimal glucose control is not just for patients who are diabetic but likely benefits all patients having cardiac operations. This message reminds me of the naysayers who said that airplanes could not fly faster than the speed of sound. Chuck Yeager (shown in Figure 1) put that misconception to bed by flying a jet at $600 \mathrm{mph}$. Surgeons should probably think like Chuck Yeager and treat blood sugars during the perioperative period with appropriate safeguards and despite fears of too-low blood sugars. I suspect that publication of this article will stimulate a robust discussion and serve to broaden the impact of glucose control following cardiac operations.

\section{References}

1. Corazzari C, Matteucci M, Kolodziejczak M, Kowalewski M, Formenti AM, Giustina A, et al. Impact of preoperative glycometabolic status on outcomes in cardiac surgery: systematic review and meta-analysis. J Thorac Cardiovasc Surg. 2022;164:1950-60.e10.

2. Vogel TR, Smith JB, Kruse RL. The association of postoperative glycemic control and lower extremity procedure outcomes. J Vasc Surg. 2017;66:1123-32.

3. Robich MP, Krafcik BM, Shah NK, Farber A, Rybin D, Siracuse JJ. Analysis of "never events" following adult cardiac surgical procedures in the United States. J Cardiovasc Surg (Torino). 2017;58:755-62.

4. Rao RH, Perreiah PL, Cunningham CA. Monitoring the impact of aggressive glycemic intervention during critical care after cardiac surgery with a glycemic expert system for nurse-implemented euglycemia: the MAGIC GENIE Project. J Diabetes Sci Technol. 2021;15:251-64. 